\title{
Air demand estimation in bottom outlets with the particle finite element method.
}

\section{Susqueda Dam case study}

Fernando Salazar • Javier San-Mauro • Miguel Ángel Celigueta •

Eugenio Oñate

Received: date / Accepted: date

F. Salazar · J. San-Mauro · M. Á. Celigueta · E. Oñate

Centre International de Mètodes Numèrics en Enginye-

ria (CIMNE). Universitat Politècnica de Catalunya (UPC),

Campus Norte UPC, Gran Capitán s/n. 08034. Barcelona,

Spain

Tel.: +34-934-071-495

F. Salazar

E-mail: fsalazar@cimne.upc.edu

J. San Mauro

E-mail: jsanmauro@cimne.upc.edu

M.Á. Celigueta

E-mail: maceli@cimne.upc.edu

E. Oñate

E-mail: onate@cimne.upc.edu 


\title{
Air demand estimation in bottom outlets with the particle finite element method.
}

\section{Susqueda Dam case study}

\begin{abstract}
Dam bottom outlets play a vital role in dam operation and safety, as they allow controlling the water surface elevation below the spillway level. For partial openings, water flows under the gate lip at high-velocity and drags the air downstream of the gate, which may cause damages due to cavitation and vibration. The convenience of installing air vents in dam bottom outlets is well known by practitioners. The design of this element depends basically on the maximum air flow through the air vent, which in turn is a function of the specific geometry and the boundary conditions. The intrinsic features of this phenomenon makes it hard to analyse either on site or in full scaled experimental facilities. As a consequence, empirical formulas are frequently employed, which offer a conservative estimate of the maximum air flow. In this work, the particle finite element method was used to model the air-water interaction in Susqueda Dam bottom outlet, with different gate openings. Specific enhancements of the formulation were developed to consider air-water interaction. The results were analysed as compared to the conventional design criteria and to information gathered on site during the gate operation tests. This analysis suggests that numerical modelling with the PFEM can be helpful for the design of this kind of hydraulic works.
\end{abstract}

Keywords Particle finite element method · Two fluids · Bottom outlets · Air demand

\section{Introduction}

Air-water interaction is a relevant phenomenon in multiple hydraulic works involving high-velocity free-surface flows, such as spillways and bottom outlets [37]. Under this conditions, the turbulent flow produces air entrainment, which results in flow bulking. Hence, the density of the aerated flow is given by $\rho_{w}(1-V)+$ $\rho_{a}(V) \approx \rho_{w}(1-V)$, where $\rho_{w}$ is the water density, $\rho_{a}$ is the air density and $V$ is the void fraction [6].

The practical consequences of this phenomenon are diverse. Flow bulking favours the energy dissipation and results in a water-solid friction reduction. [40]. 


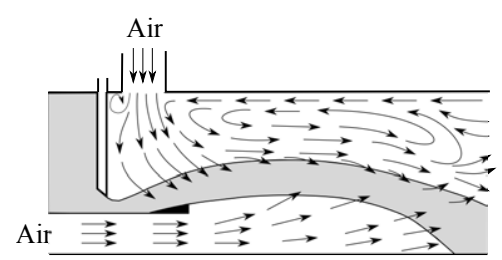

Fig. 1 Typical flow pattern in high-head bottom outlets. Adapted from [36]

In spillway chutes and open channels, aeration produces an increase of the effective depth, so that a larger section is needed to avoid wall overtopping.

In bottom outlets, there is a need to allow and even encourage air entrance to avoid the formation of negative pressures that can damage the structure [42]. To this end, a conduit is typically installed in the downstream side of the gate, which allows air supply. The design of this element is mostly based on the maximum air demand, i.e., the maximum air flow to be conducted within the gate operation range.

The occurrence of major breakdowns in Roosevelt and Pathfinder dams [9] revealed this need, and encouraged several authors to investigate the phenomenon. As a result, several systematic experimental campaigns were carried out with the aim of deriving empirical formulas [35], [4], as well as identifying the most influential factors.

Thus, it was observed that the aerated flow pattern downstream of a high-head gate essentially depends on [36]:

- The upstream and downstream boundary conditions

- The gate opening

- The presence of bottom aerators

- The geometry of the conduit

Fig. 1 depicts the typical flow pattern in a partially-opened high-head gate with bottom aerator.

Although the phenomenon was the subject of numerous studies in the past, the hydraulic behaviour of aerated flows in bottom outlets is not fully understood and depends on each particular case. Hydraulic modelling on experimental facilities at convenient scale is typically recommended [41].

As a first approximation for a preliminary design, the formulas proposed by Sharma [35] are frequently used. They are conservative, since they are based on the envelope of the maximum values obtained in laboratory for each situation. Different expressions are recommended in function of the flow regime in the conduit. The same author identified six types of aerated flow regimes in bottom outlets, as a function of the gate opening and the downstream boundary conditions (Fig. 2).

The applicability of these formulas is limited, because they are based on results of small-scale tests. Moreover, they were performed on square conduits, while many bottom outlets feature round sections.

Tullis and Larchar [38] proposed a general methodology for designing the aeration system, also based on experimental results. Nonetheless, this method is specific for small to medium-sized embankment dams with an inclined slide gate.

These methods are far from being generally applicable. As a result, it is frequent, in practice, to perform specific experimental tests (e. g. [31], [38], [11]). 


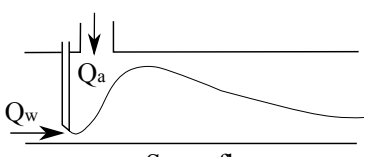

Spray flow

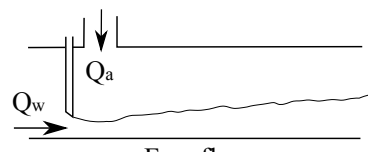

Free flow

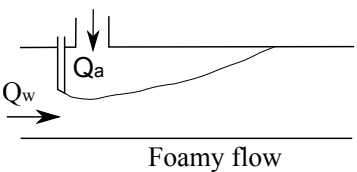

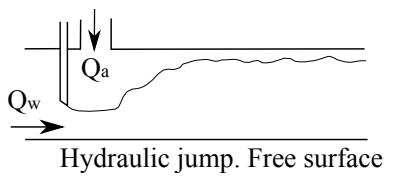
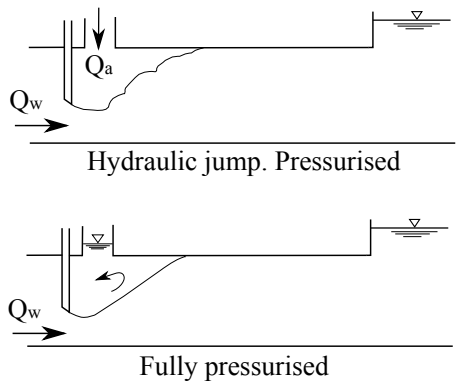

Fig. 2 Types of aerated flow regimes in bottom outlets, as defined by Sharma [35]. $Q_{a}=$ air flow; $Q_{w}=$ water flow;

Numerical modelling is an obvious alternative to these empirical and experimental approaches. However, the complexity of the air-water interaction phenomenon prevented practitioners from its application. The problem is three-dimensional, and requires considering two fluids which strongly interact by means of diverse processes [6]: the turbulence induces free-surface breakup which allows air entrainment into the water flow; the entrapped air may travel within the flow in bubbles and droplets of a broad range of sizes; these can collide and eventually join, or exit again if the appropriate flow conditions occur.

The direct simulation of these processes is infeasible, but they can be considered at a macroscopic scale producing useful results for practical purposes. Some formulations exist to consider the turbulent air entrainment coupled with variable density estimation, such as that implemented in the commercial software Flow3D [12]. Some examples of application to spillway hydraulics were already published [40]. In general, the objective is to calculate the macroscopic variables (air concentration, and especially air flow), which suffice to determine the appropriate geometry of the aeration system. Other commercial softwares such as ANSYS use a similar approach [2], also based on the volume of fluid (VOF) model [20]. The main drawback of this method is that convenient models need to be chosen for air entrainment and flow turbulence, whose parameters require a detailed calibration process.

The authors have implemented a particular class of Lagrangian formulation for solving problems involving complex interactions between free surface fluids. The so-called Particle Finite Element Method (PFEM) tracks the trajectory of the nodes of the mesh, including those on the free surface or in a fluid-fluid interface, and is even able to model the separation of parts of the domain, such as droplets. A mesh connects the nodes discretising the domain where the governing equations are solved using a stabilised version of the Finite Element Method (FEM). Details of the PFEM can be found in [1], [24], [27], [19], [15], [16], [3], [34].

With the PFEM, air entrainment can be naturally modelled by means of mixed elements (combining water and air nodes). This can be done because the information in the PFEM is stored in the nodes, as opposite to Eulerian approaches. The 
density of the aerated flow is automatically computed depending on the proportion of air and water nodes in a certain sub-domain. The purpose of this approach is also to extract the macroscopic variables, rather than to model each volume of trapped air, which can appear in a broad range of sizes, from microscopic to centimetric. In particular, it is possible to quantitatively reproduce the air drag capacity of the flow, and therefore the air flow rate of a determined facility, which is the basis of the design of the aeration system. Additionally, other variables of interest can be analysed, as the pressure on the downstream face of the gate, or the velocity in the air vent.

The evolution of PFEM led to the so-called PFEM2 technique [14]. It shares most of the PFEM features while using large time steps, hence resulting in lower computational cost. Since the PFEM2 is also adequate to analyse multifluid flows [17], it could be an alternative to face the problem under consideration. Nonetheless, we chose PFEM instead of PFEM2 because a) the computational cost was not critical in our problem, and b) the first version was specifically validated for simulation of free surface flows in the field of dam hydraulics [18].

This paper presents some improvements implemented in the PFEM formulation to tackle the simulation of air-water flows, together with its application to verify the performance of the bottom outlet of Susqueda Dam. The results were analysed, both qualitatively and quantitatively, for different gate openings. They are consistent with the performance observed during the operation tests, as well as with existing design recommendations [39].

The rest of the paper is organised as follows: first, a brief introduction to the PFEM is presented, together with the description of some specific functionalities developed for this application. Then, the case study is introduced, and the numerical model set described. In the final sections, the results are shown and discussed, and some conclusions are drawn regarding future applications and developments.

\section{Numerical model}

In the PFEM, the domain is modelled using an updated Lagrangian formulation [43]. That is, all variables are assumed to be known in the current configuration at time $t$. The new set of variables in the domain are sought for in the next or updated configuration at time $t+\Delta t$. The finite element method (FEM) is used to solve the equations of continuum mechanics. Hence a mesh discretising the domain must be generated in order to solve the governing equations in the standard FEM fashion.

The equations to be solved are the Navier-Stokes equations for incompressible fluids:

Momentum conservation

$$
\rho \frac{D u_{i}}{D t}=-\frac{\partial}{\partial x_{i}} p+\mu \frac{\partial}{\partial x_{j}}\left(\frac{\partial u_{i}}{\partial x_{j}}\right)+\rho f_{i}
$$

for $i, j=x, y, z$

Mass conservation

$$
\frac{\partial u_{i}}{\partial x_{i}}=0
$$


for $i=x, y, z$

with

$$
u=\bar{u}
$$

for the solid nodes and

$$
p=0
$$

for the free surface fluid nodes.

In above equations, $\rho$ and $\mu$ are the fluid density and dynamic viscosity, respectively, $p$ is the pressure, $u_{i}$ are the velocities along the $i$ th global (cartesian) axis, $f_{i}$ are the body forces, and $\bar{u}$ is the prescribed velocity.

According with the PFEM technique [27], equations 1 and 2 are discretised with a standard FEM mesh and then solved. When the finite elements get very distorted, the mesh is re-generated, but the nodes and their information are conserved. Adaptive mesh refinement techniques can be used to improve the solution in zones where large motions of the fluid or the structure occur.

The method has been employed to face a variety of problems in different fields of engineering, such as free surface flows [19], landslides [33], [34], industrial forming processes [26], ground excavation [5], fluid-structure interaction [21], among others [23], [22], [13], [28]. The details of the algorithm and our implementation was described in previous publications [21], [24], [25]. In this paper, only the basic steps of the algorithm are succinctly described, together with some enhancements specifically implemented for the present application.

\subsection{Basic steps of the PFEM}

In the PFEM, the mesh nodes in the fluid and solid domains are treated as particles that contain all the information as regards the geometry and the material and mechanical properties of the underlying subdomains.

A typical solution with the PFEM involves the following steps.

1. The starting point at each time step is the cloud of points $C$ in the fluid and solid (boundary) domains. For instance, ${ }^{n} C$ denotes the cloud at time $t={ }^{n} t$ (Fig. 3).

2. The domain is discretised with a finite element mesh ${ }^{n} M$ using the particles as the mesh nodes. We use an efficient mesh generation scheme based on the Delaunay tesselation [16].

3. The free surface is detected by means of the Alpha Shape Method [8], which removes big and distorted elements.

4. The Lagrangian equations of motion for the overall continuum are solved using the standard FEM. The state variables in the next (updated) configuration for ${ }^{n} t+\Delta t$ are computed: velocities, pressure, strain rate and viscous stresses.

5. The mesh nodes are moved to a new position ${ }^{n+1} C$ where $n+1$ denotes the time ${ }^{n} t+\Delta t$, in terms of the time increment size.

6. Go back to step 1 and repeat the solution for the next time step to obtain a new ${ }^{n+1} C$. 


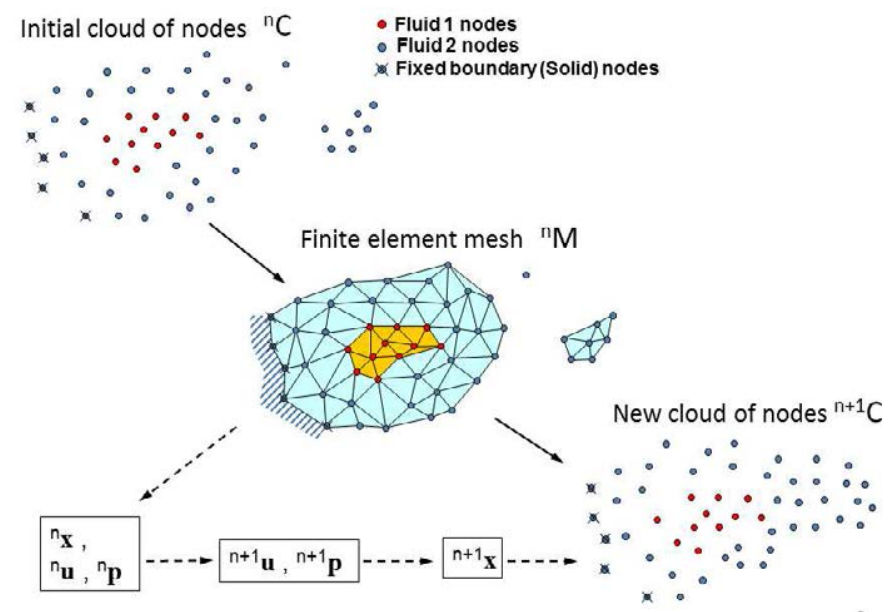

Fig. 3 Sequence of steps to update a "cloud" of particles (nodes) representing a domain containing two fluids and a solid boundary from ${ }^{n} t$ to ${ }^{n+1} t$ (colour figure online).

\subsection{Mesh quality maintenance operations}

It was previously mentioned that PFEM is suitable for modelling fluids in which the free surface suffers severe distortions during the transient solution. In the case of aeration in bottom outlets, a fluid (water) enters at high velocity into a domain initially occupied by another fluid (air) at rest. This implies a greater difficulty for maintaining a sufficient quality mesh during the calculation. To ensure this quality, some improvements in the meshing algorithm have been implemented, as described below.

Removing nodes: Usually, the computations carried out with the PFEM tend to create very distorted meshes. This means that the nodes, when following their trajectories in a Lagrangian fashion, can get very close one to another. Sometimes, two, three or more nodes join in a reduced space, generating very distorted elements with near null volume and a high aspect ratio. To avoid this problem, the authors have adopted a method consisting on removing one node of the mesh if it detects that another is present at a short distance (a fraction of $h$, where $h$ is the desired/imposed mesh size). During the generation of the Delaunay Tessellation, for which the incremental insertion method is used [7], if the node to be inserted is marked with a special flag, it is not inserted. By doing this, the final connectivities of the mesh do not include the removed node, but do have elements that connect the remaining nodes according to the Delaunay Tessellation (Fig. 4).

Adding nodes: When the Delaunay Tessellation is complete, the resulting elements filling the space previously occupied by a removed node might be bigger than the desired size. If nothing is done, the Alpha-shape method might remove these elements, resulting in a void in the interior of the fluid, the free surface condition would be imposed on the nodes next to the void and the fluid pressure field would be spoiled. There must be then another mesh reparation step before the 


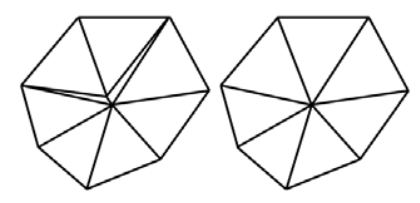

Fig. 4 Mesh quality maintenance by removing a node that forms distorted elements

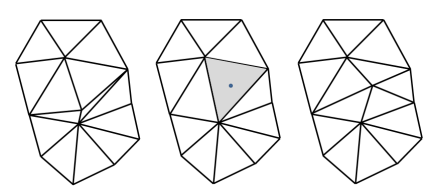

Fig. 5 Node insertion to enhance mesh quality after removing a node

Alpha-shape method is applied. Those elements bigger than a certain size (measured with the circumradius) must be refined by adding a node in the circumcenter of the element (Fig. 5). This step must be done far from the free surface detected in the last time step, or the Alpha-shape method would never remove any element. A local Delaunay Tessellation is enough for each node inserted.

\subsection{Modelling water and air}

For modelling water that fills a pipe (or a cavity) full of air, the whole domain was filled with air nodes and the water was injected from one of the sides. The density of an element is taken as the average of the densities of the nodes of the element. The fluid mixture is solved as a single fluid with a heterogeneous density. When two nodes of different material get too close and the mesh is too distorted, one of the nodes must be removed. The water node is considered prevalent, so the air node is removed. If one node must be added, its material will be that of the nodes which are in majority. With this approach, the mass conservation of each fluid is not enforced geometrically. However, the water behaviour is very similar to that observed in the PFEM computations with a single fluid (no air) and the free surface is modelled as a null pressure condition.

The typical velocities and pressures of this problem do not require treating the air as a compressible fluid, so the mass conservation equation imposes a divergencefree velocity field even for those parts of the domain that represent the air.

Neither the turbulence nor the surface tension between water and air were accounted for in this work, since they do not play a significant role at the mesh scale used, which is of the order of centimetres. As a result, small-scale effects, such as small bubbles that are formed and trapped by the turbulent flow of the water, cannot be modelled in full detail. Nonetheless, the numerical modelling with PFEM can be useful to obtain an estimation of the air flow demand for different situations, which is essential for designing the aeration system. 


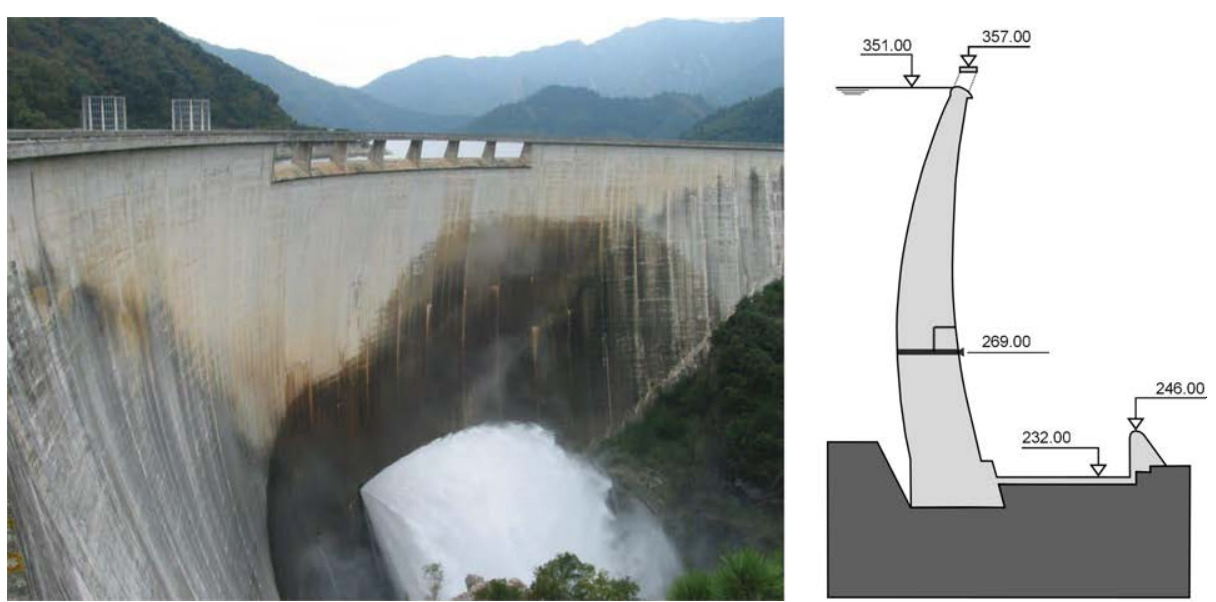

Fig. 6 Susqueda Dam. Left: view from the right abutment with one outlet in operation (courtesy of F.J. Conesa); Right: cross-section through a bottom outlet

\section{Susqueda Dam case study}

Susqueda Dam (Fig. 6) is located at the Ter river basin, in the north-eastern region of Spain. It is a double-curvature arch dam with a maximum height of $\mathrm{m}$ above foundation. The bottom outlets are situated at $37 \mathrm{~m}$ above the stilling basin. They comprise four round conduits of $1.5 \mathrm{~m}$ diameter. Each one is controlled by two identical flat-seat round-section valves [30]: that installed upstream serves as a guard gate, whereas the one in the downstream part is used for flow regulation.

This type of valves were developed for circular conduits to join the robustness of the conventional bonneted slide gates [10], [32], while avoiding the need for round-to-square upstream transition and square-to-round downstream transition [30]. Thus, the results of the conventional formulas and the design criteria for the aeration system need to be verified for its application to this typology.

The bottom outlets at Susqueda Dam feature a $4-\mathrm{m}$ reach from the downstream face of the regulation gate to the downstream face of the dam (Fig. 7). A deflector was installed at the end of the conduit to improve energy dissipation by widening the flow impact area. It comprises a cone-shaped plate. The aeration system consists of a $0.4-\mathrm{m}$ diameter air conduit, with a vertical $4-\mathrm{m}$ long reach, a $90^{\circ}$ elbow, and a horizontal 3.5-m long reach which also ends at the downstream dam face (Fig. 7).

\section{Numerical model set}

\subsection{Geometry and mesh}

The numerical model reproduces one of the bottom outlets of Susqueda Dam. The upstream guard gate was not considered in the computation, since it remains fully open during normal operation. As a result, the model geometry comprised a 1.5 $\mathrm{m}$ diameter conduit, a partially-opened gate with $0.3 \mathrm{~m}$ thickness, and a $0.4 \mathrm{~m}$ 


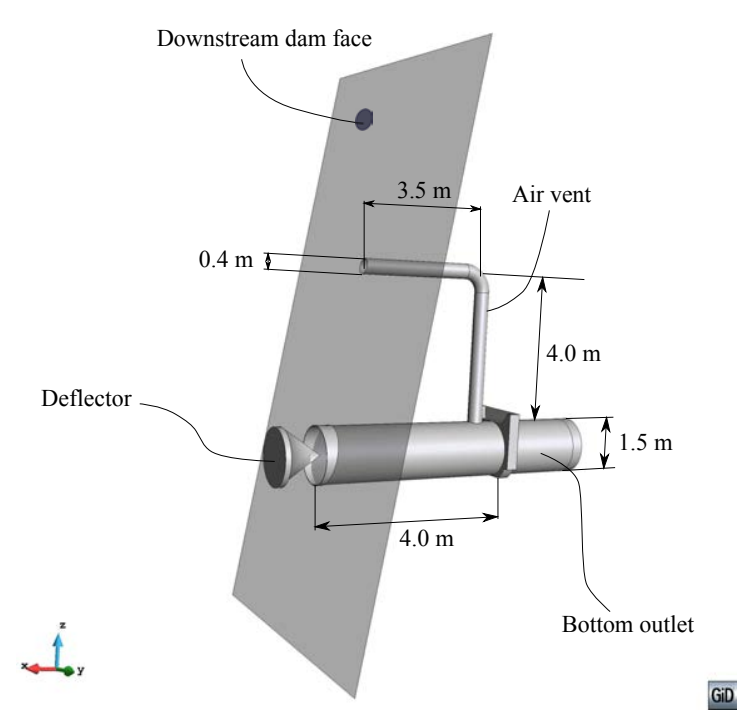

Fig. 7 Geometry of the bottom outlet in the numerical model. Perspective.

diameter air vent with a $90^{\circ}$ elbow. Fig. 7 depicts the more relevant aspects of the model geometry.

Both the outlet end section and the exit of the air vent are connected to a large volume, initially filled with air, which represents the domain at the downstream area of the dam body. Fig. 8 shows the main dimensions of the overall computational domain.

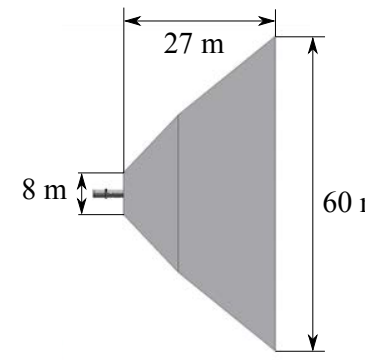

(a) Plane view

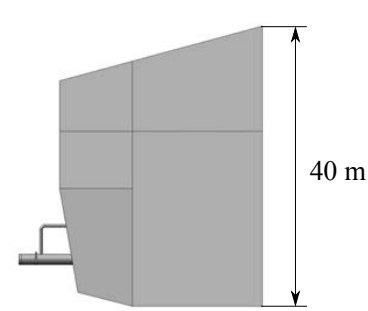

(b) Side view

Fig. 8 Overall view of the computational domain, including the air surrounding the downstream face of the dam.

PFEM allows considering different mesh sizes within certain sub-domains. This is useful to optimise the computational resources, as a fine mesh can be used in the areas of interest, while other regions can be meshed with larger elements. In this implementation of the PFEM, the mesh size is defined by means of nested parallelepiped, sharing the same centre. They feature increasing mesh sizes in the inside-outside direction, from 0.07 to $1.6 \mathrm{~m}$. Fig. 9 shows a detail of the different 


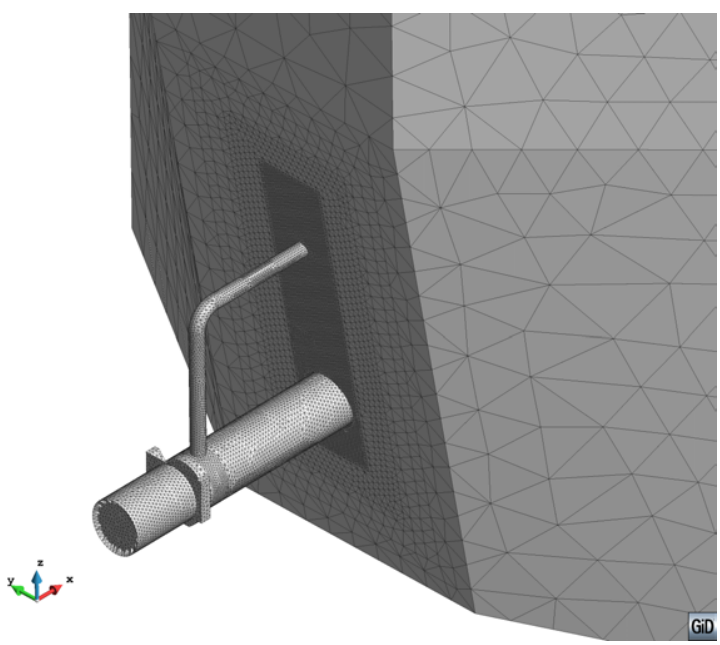

Fig. 9 Variable mesh size.

Table 1 Inflow discharge for each gate opening

\begin{tabular}{ll}
\hline Gate opening $(\%)$ & Inflow $\left(m^{3} s^{-1}\right)$ \\
\hline 25 & 10.94 \\
50 & 20.73 \\
75 & 33.84 \\
80 & 36.19 \\
90 & 40.59 \\
100 & 44.18 \\
\hline
\end{tabular}

mes sizes. The software GiD [29] was employed for geometry and mesh generation and results post-process.

\subsection{Boundary conditions}

In all cases, the upstream hydraulic head was set to $0.49 \mathrm{MPa}$, equivalent to 50 $\mathrm{m}$ of water. Since the study focused on the aeration system, the upstream water volume (from the upstream side of the gate to the reservoir free surface) was not considered. As an alternative, the incoming flow rate for each gate opening was computed by means of a separate numerical simulation (not described here), whose results are included in table 1.

The downstream volume was limited by solid boundaries, except by a $12 \times 5$ $\mathrm{m}$ surface where zero pressure was imposed. 


\section{Results and discussion}

\subsection{Flow regime}

The downstream water level is not relevant in Susqueda Dam, as the outlet exits at a sufficient height over the stilling basin so as to avoid drowning. However, the deflector introduces a localised head loss, which may modify the expected flow regime for a free discharge conduit. As a result, it was considered interesting to analyse the air-water interaction in the conduit, between the gate and the deflector. The results are presented in Fig. 10 for each gate opening.

As expected, the gate opening conditioned the air-water interaction. As it increased, a greater portion of the conduit was filled with water. The flow regime varied: it can be classified as spray flow for $25 \%$ opening; free flow for $50-80 \%$, and foamy flow for $90 \%$. For full gate opening, the water also flowed through the air vent, showing no air demand and a fully pressurised flow (Fig. 11). The latter behaviour was also observed on site, as depicted in Fig. 11. It should be noted that the water exits at low pressure through the air vent.

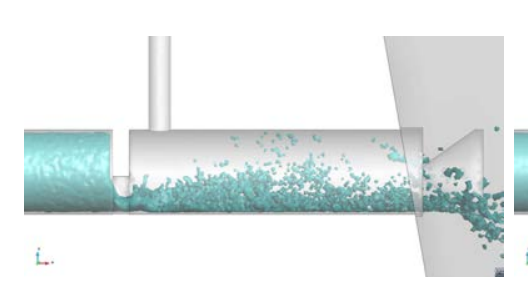

(a) $25 \%$ gate opening

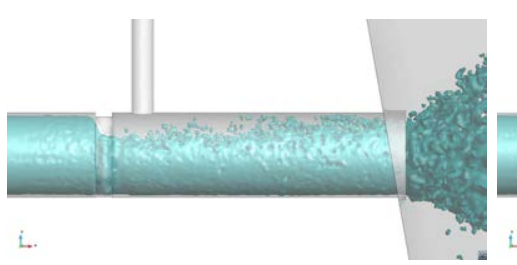

(c) $75 \%$ gate opening

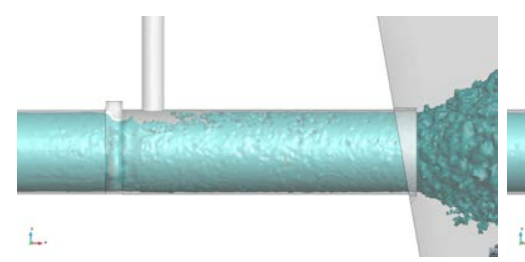

(e) $90 \%$ gate opening

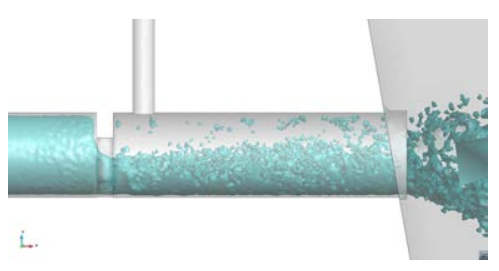

(b) $50 \%$ gate opening

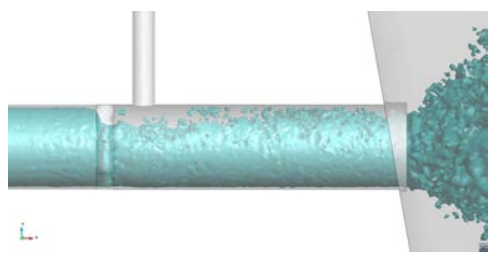

(d) $80 \%$ gate opening

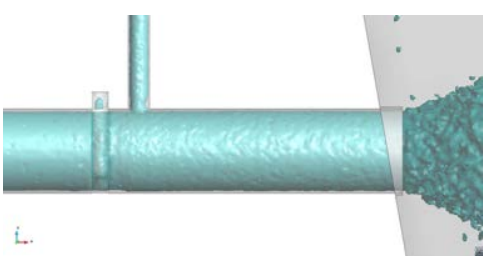

(f) $100 \%$ gate opening

Fig. 10 Flow regime in the outlet for different gate openings. Iso-surface of density $=500$ $\mathrm{kg} / \mathrm{m}^{3}$. (Colour figure online). 

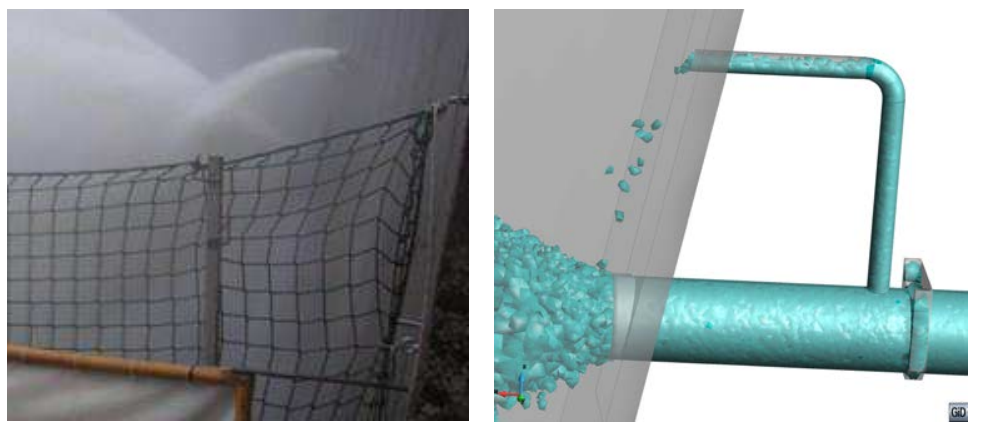

Fig. 11 Water flowing through the air vent for $100 \%$ gate opening. Left: image taken during the gate operation tests. Right: numerical model results. (Colour figure online).

\subsection{Air flow pattern}

The flow pattern of both fluids was analysed, both in the air vent and in the outlet. To that end, the velocity vectors were drawn on a longitudinal section of the model, as depicted in Fig. 12. The objective was to compare the velocity field for various gate openings to those defined by Sharma (Fig. 2).

It was observed that for small gate openings (up to $50 \%$ ), the air demand was satisfied both from the air vent and from the downstream end of the outlet (it entered through the area around the deflector which is free from the water flow).

Between 75 and $90 \%$ gate opening, all the air was supplied by the air vent, since most of the outlet section was occupied by the water flow. In these cases, a recirculating area appeared at the top of the conduit, where part of the air flow was trapped by the high-velocity water flow at the bottom, while the mixture was evacuated around the deflector.

Finally, as mentioned in the previous section, the water completely filled the conduit for $100 \%$ gate opening. In this situation there was no air demand, and part of the water exited through the air vent towards the downstream face of the dam body with low pressure.

A more detailed analysis was carried out for 25, 50, 75 and $90 \%$ gate opening. Fig. 13 shows results in four cross-sections between the gate and the deflector: a) the contour for $95 \%$ air concentration $(C=0.95)$, and b) the sign of the velocity in the $\mathrm{x}$-axis direction. It can be seen that for small openings the water concentrated at the bottom central area, while part of the air was dragged towards the deflector $\left(v_{x}>0\right)$. By contrast, for large openings only the top-central zone featured $C \geq 95 \%$.

In the Fig. 14 only the air nodes are plotted, separated by the sign of their $\mathrm{x}$-velocity. The air flow from the deflector area for $25-50 \%$ gate opening can be clearly observed, as well as the small volume occupied by air for $90 \%$ opening. The ratio of air nodes with positive $\mathrm{x}$-velocity increased with large gate openings.

\subsection{Air flow rate}

The air vent design (axis and diameter) is mostly based on the maximum air flow. In the general case, the problem is coupled, i.e. the air demand depends 


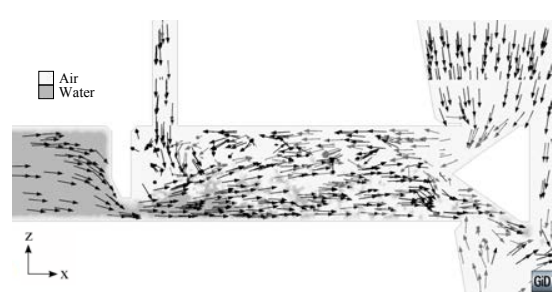

(a) $25 \%$ gate opening

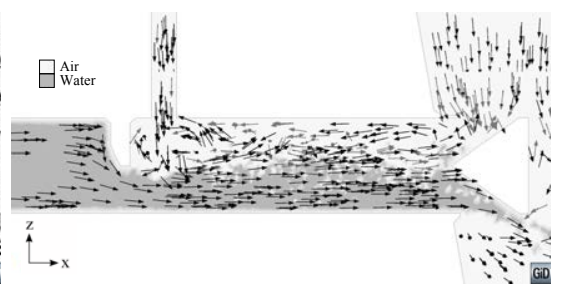

(b) $50 \%$ gate opening

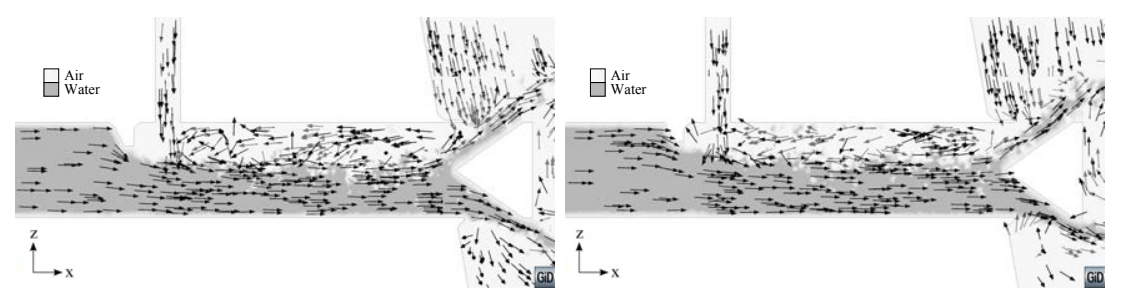

(c) $75 \%$ gate opening

(d) $80 \%$ gate opening

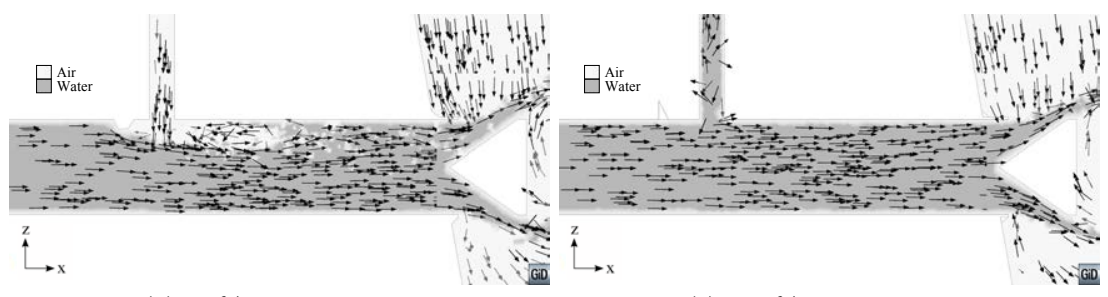

(e) $90 \%$ gate opening

(f) $100 \%$ gate opening

Fig. 12 Velocity vectors for different openings. Longitudinal section. The dark area depicts air concentration $\leq 50 \%$

on the geometry of the air vent. In this particular case study, the design was already decided and built, and the numerical modelling was carried out as a further verification.

The air flow rate for each gate opening was computed by integrating the velocity field in a horizontal section of the air vent. The result was averaged over five seconds of simulation (from $t=1 \mathrm{~s}$ to $t=6 \mathrm{~s}$ ), once a pseudo-stationary regime was reached (in the beginning of the simulation, the incoming water flow pushes the air). The results are presented in Fig. 15.

It can be observed that the maximum air demand is registered for $80 \%$ gate opening. This value coincides with the practical criteria suggested by some authors (e.g. [36], [39], [4]). Nonetheless, it should be mentioned that according to some publications, the gate opening for the maximum air flow rate depends on the specific features of each facility. For instance, Tullis and Larchar reported a maximum air demand for $50 \%$ gate opening [38]. Their experimental study focused on slide gates installed on the upstream sloping face of embankment dams.

The velocity values (and consequently also the flow rate) showed high fluctuation for some gate openings along the period considered. This was also observed in experimental tests [38], and was attributed to the high turbulence and instability of the flow downstream of the gate. Fig. 15 also shows the standard deviation of the flow rate for each gate opening. 


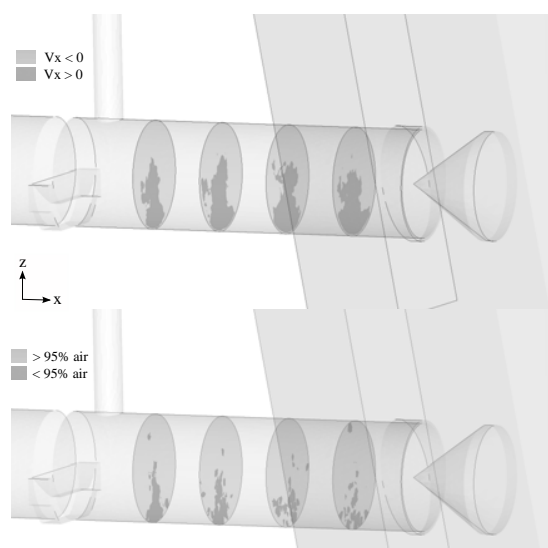

(a) $25 \%$ gate opening

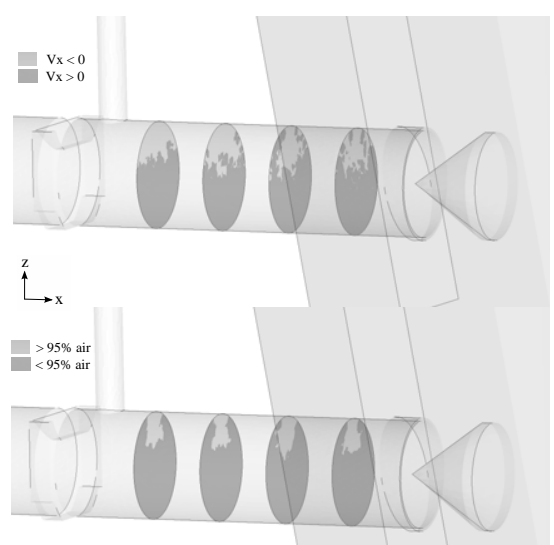

(c) $75 \%$ gate opening

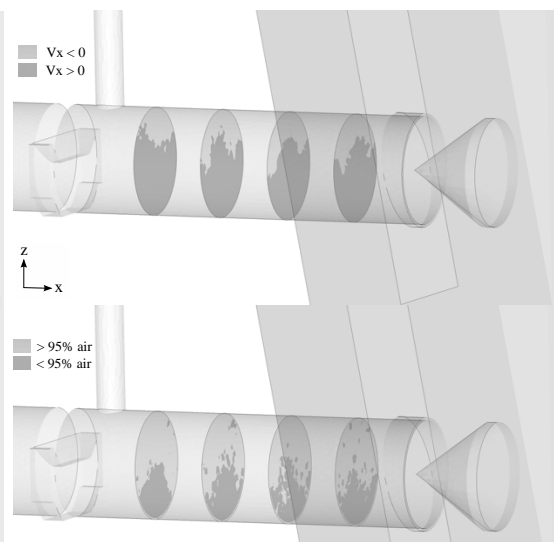

(b) $50 \%$ gate opening

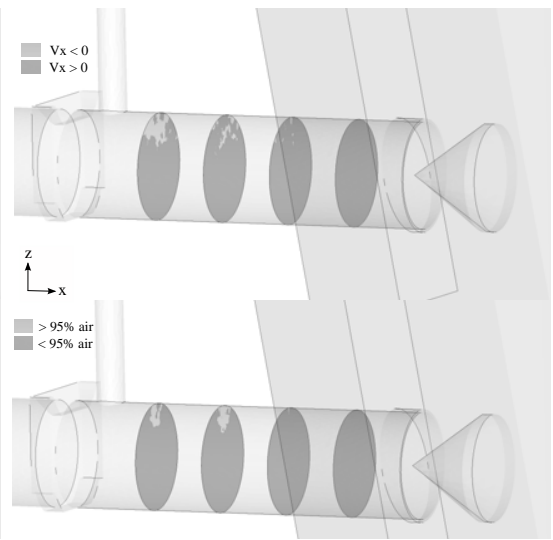

(d) $90 \%$ gate opening

Fig. 13 Air-water interaction downstream of the air vent. Cross sections at 1.5, 2.5, 3.5 and $4.5 \mathrm{~m}$ from the gate. For each gate opening, the sign of the x-velocity (top) and the air concentration (bottom) are plotted. It should be noted that the darker region in the bottom figures represents the area occupied by the aerated flow (0-95\% air concentration).

The maximum velocity in the air vent was also verified, as this is the fundamental parameter its design. Fig. 16 shows that the relation between gate opening and maximum velocity sensibly coincides with that for the mean air flow, although the absolute maximum was recorded for $90 \%$ gate opening: an instant value of 33 $\mathrm{m} / \mathrm{s}$ was obtained. Since the typical recommendation is to limit the maximum velocity to $45 \mathrm{~m} / \mathrm{s}$ ([39], [4]), it can be concluded that the aeration for Susqueda Dam was correctly dimensioned.

These results might seem contradictory as compared to those depicted in Fig. 13: the higher air demand coincides with gate openings for which the area occupied by water is greater. However, it should be noted that for small openings most of the air circulates with negative velocity in the x-axis, i.e., it comes from the area around the deflector. By contrast, for $75-90 \%$ gate opening all the air demand is 


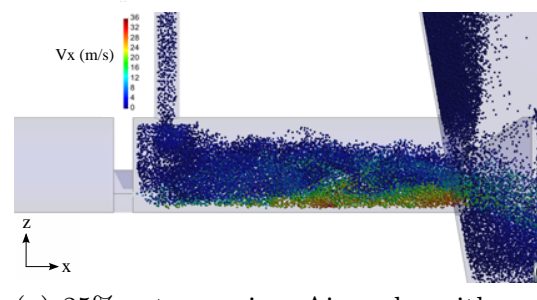

(a) $25 \%$ gate opening. Air nodes with positive x-velocity
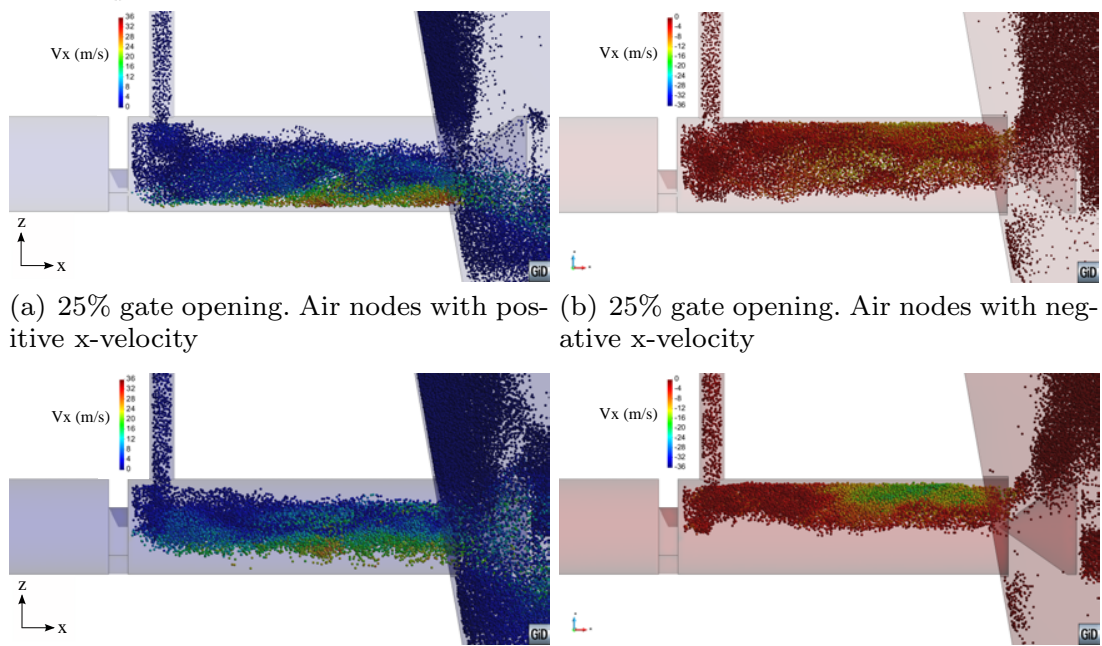

b) $25 \%$ gate opening. Air nodes with negative $\mathrm{x}$-velocity

(c) $50 \%$ gate opening. Air nodes with pos-

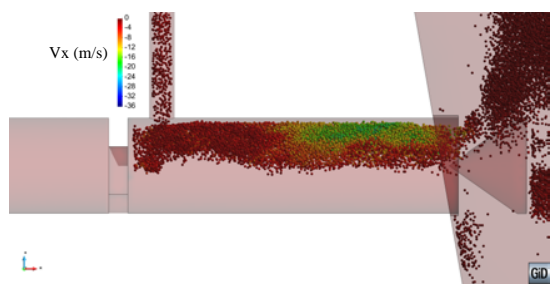

itive $\mathrm{x}$-velocity

(d) $50 \%$ gate opening. Air nodes with neg-

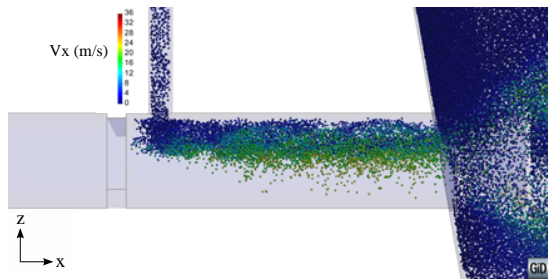
ative $\mathrm{x}$-velocity

(e) $75 \%$ gate opening. Air nodes with positive $\mathrm{x}$-velocity
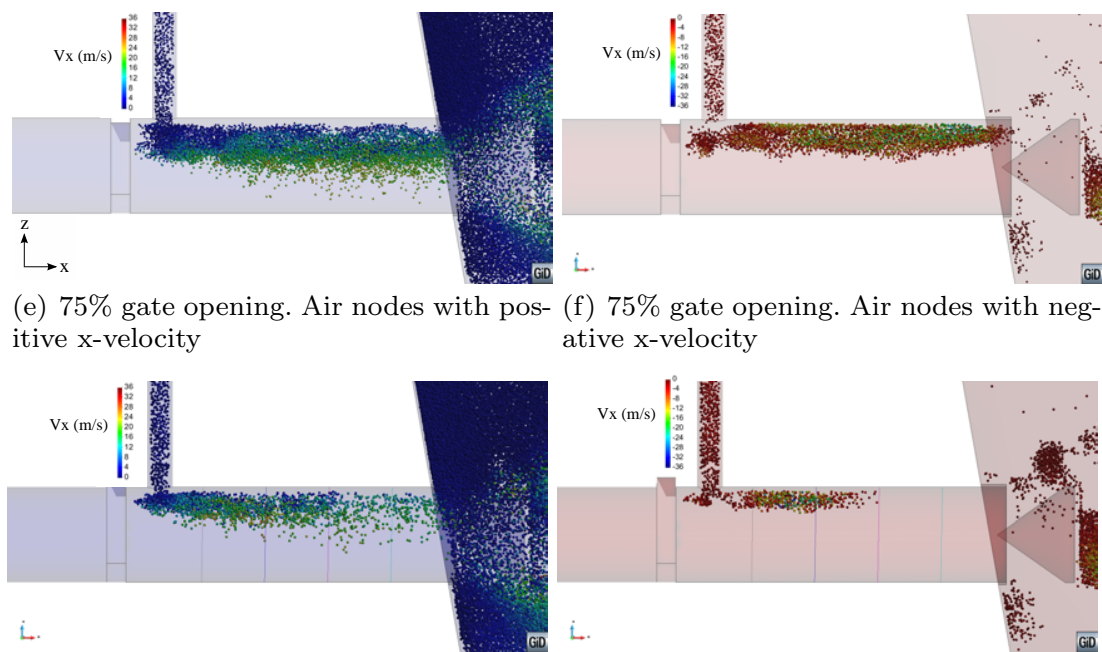

(f) $75 \%$ gate opening. Air nodes with negative $\mathrm{x}$-velocity

(g) $90 \%$ gate opening. Air nodes with pos- (h) $90 \%$ gate opening. Air nodes with negitive $\mathrm{x}$-velocity

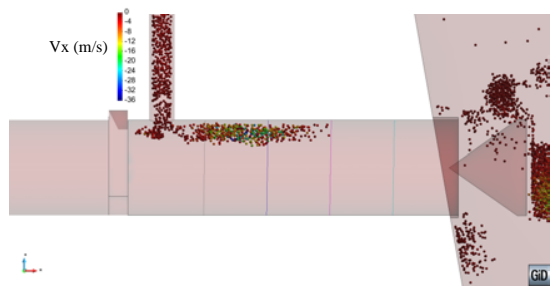

Fig. 14 Air nodes for 25, 50, 75 and 90\% gate opening, separated by the sign of the x-velocity. Most of the air is supplied from the deflector area for small gate openings. (Colour figure online)

supplied by the air duct, the re-circulation area is smaller, and the air velocity is higher. These factors result in greater air flow through the air vent (Fig. 14).

\section{Summary and conclusions}

The PFEM was applied to simulate the air-water interaction in the downstream reach of Susqueda Dam bottom outlet. Different gate openings were analysed for 


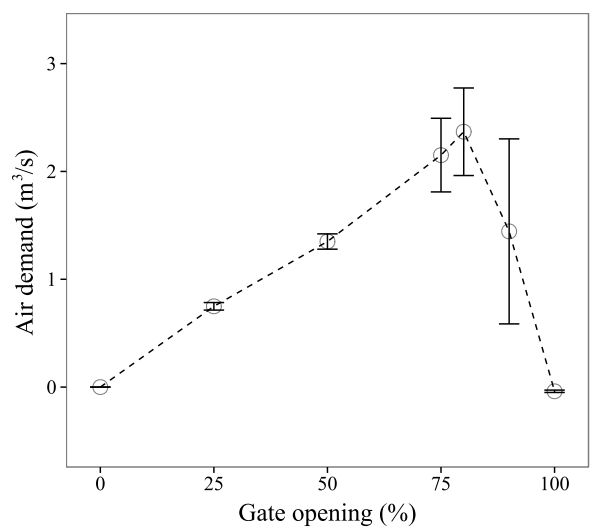

Fig. 15 Air flow rate as a function of the gate opening. The bars show the standard deviation. The maximum air demand was registered for $80 \%$ opening.

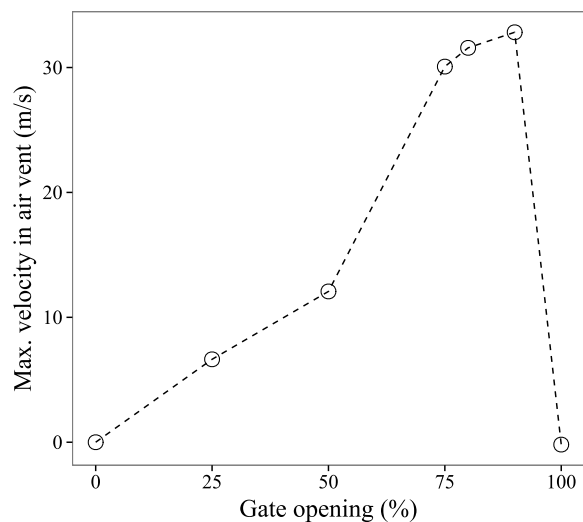

Fig. 16 Maximum instant air flow velocity in the vent as a function of the gate opening.

a constant upstream head. In the PFEM, the information is stored at the nodes of the mesh, which is regenerated at every time step. Thus, air-water mixture can be naturally modelled by means of mixed elements (formed by nodes from air and water).

The phenomenon is highly complex, with a broad range of air and water particle sizes. Although the direct simulation of every droplet and bubble is infeasible, PFEM allows considering the air drag produced by the high-velocity water flow, as well as analysing the air-water flow pattern.

The numerical results were analysed and compared to previous studies and common design criteria. The main conclusions that can be drawn from that analysis are:

- Some of the flow regimes defined by Sharma [35] were observed for increasing gate openings: from spray flow with $25 \%$ opening to fully pressurised flow for $100 \%$ opening. Free and foamy flows were also observed for intermediate gate openings. 
- The maximum air demand on average was recorded for $80 \%$ gate opening, which is in accordance with the reference studies and design guides ([38], [39], $[36])$.

- For full opening, the conduit is fully pressurised and part of the water flow fills the air vent. Thus, the air demand is null in this situation. This behaviour was observed on site during the operation tests (Fig. 11).

The results suggest that the PFEM can be useful for calculating the air demand in dam bottom outlets. In the case study presented, the appropriateness of the existing design was verified. For new facilities, the possibilities of the PFEM for identifying the flow patterns, and for computing the pressure and velocity fields should be helpful for designing the aeration system.

Acknowledgements The authors thank Felipe Río and Francisco J. Conesa, from ENDESA GENERACION, for supplying the information about Susqueda Dam, and Francisco Riquelme for promoting this research. It was carried out with financial support received from the FLOODSAFE project funded by the Proof of Concept Program of the European Research Council.

\section{References}

1. The Particle Finite Element Method - PFEM. URL http://www.cimne.com/pfem/

2. ANSYS Inc.: Ansys Fluent theory guide (2011)

3. Aubry, R., Idelsohn, S., Oñate, E.: Particle finite element method in fluid-mechanics including thermal convection-diffusion. Computers \& Structures 83(17-18), 1459-1475 (2005)

4. Campbell, F., Guyton, B.: Air demand in gated conduits. In: IAHR Symposium, Minneapolis (1953)

5. Carbonell, J.M., Oñate, E., Suárez, B.: Modeling of ground excavation with the particle finite-element method. Journal of Engineering Mechanics 136(4), 455-463 (2009)

6. Chanson, H.: Hydraulics of aerated flows: qui pro quo? Journal of Hydraulic Research 51(3), 223-243 (2013)

7. Cheng, S.W., Dey, T.K., Shewchuk, J.: Delaunay mesh generation. CRC Press (2012)

8. Edelsbrunner, H., Mücke, E.P.: Three-dimensional alpha shapes. ACM Transactions on Graphics 13(1), 43-72 (1994)

9. Erbisti, P.C.: Design of hydraulic gates. CRC Press (2014)

10. FEMA: Outlet works energy dissipators. Tech. Rep. P-679 (2010)

11. Frizell, K.: Hydraulic model studies of aeration enhancements at the folsom dam outlet works: Reducing cavitation damage potential. Water Operation and Maintenance Bulletin (185) (2004)

12. Hirt, C.W.: Modeling turbulent entrainment of air at a free surface. Flow Science, Inc (2003)

13. Idelsohn, S., Mier-Torrecilla, M., Oñate, E.: Multi-fluid flows with the particle finite element method. Computer Methods in Applied Mechanics and Engineering 198(33), 27502767 (2009)

14. Idelsohn, S., Nigro, N., Limache, A., Oñate, E.: Large time-step explicit integration method for solving problems with dominant convection. Computer Methods in Applied Mechanics and Engineering 217, 168-185 (2012)

15. Idelsohn, S., Oñate, E., Del Pin, F.: A lagrangian meshless finite element method applied to fluid-structure interaction problems. Computers and Structures 81(8), 655-671 (2003)

16. Idelsohn, S., Oñate, E., Pin, F.D.: The particle finite element method: a powerful tool to solve incompressible flows with free-surfaces and breaking waves. International Journal for Numerical Methods in Engineering 61(7), 964-989 (2004)

17. Idelsohn, S.R., Marti, J., Becker, P., Oñate, E.: Analysis of multifluid flows with large time steps using the particle finite element method. International Journal for Numerical Methods in Fluids 75(9), 621-644 (2014) 
18. Larese, A., Rossi, R., Oñate, E., Idelsohn, S.: Validation of the particle finite element method (pfem) for simulation of free surface flows. Engineering Computations: Int J for Computer-Aided Engineering 25(4), 385-425 (2008)

19. Larese, A., Rossi, R., Oñate, E., Idelsohn, S.R.: Validation of the particle finite element method (PFEM) for simulation of free surface flows. Engineering Computations 25(4), 385-425 (2008)

20. Liu, T., Yang, J.: Three-dimensional computations of water-air flow in a bottom spillway during gate opening. Engineering Applications of Computational Fluid Mechanics 8(1), 104-115 (2014)

21. Oñate, E., Idelsohn, S.R., Celigueta, M.A., Rossi, R.: Advances in the particle finite element method for the analysis of fluid-multibody interaction and bed erosion in free surface flows. Computer Methods in Applied Mechanics and Engineering 197(19), 1777-1800 (2008)

22. Oñate, E., Rossi, R., Idelsohn, S.R., Butler, K.M.: Melting and spread of polymers in fire with the particle finite element method. International Journal for Numerical Methods in Engineering 81(8), 1046-1072 (2010)

23. Oñate, E., Celigueta, M.A., Idelsohn, S.R.: Modeling bed erosion in free surface flows by the particle finite element method. Acta Geotechnica 1(4), 237-252 (2006)

24. Oñate, E., Celigueta, M.A., Idelsohn, S.R., Salazar, F., Suárez, B.: Possibilities of the particle finite element method for fluid-soil-structure interaction problems. Computational Mechanics 48(3), 307-318 (2011)

25. Oñate, E., Franci, A., Carbonell, J.M.: Lagrangian formulation for finite element analysis of quasi-incompressible fluids with reduced mass losses. International Journal for Numerical Methods in Fluids 74(10), 699-731 (2014)

26. Oñate, E., Franci, A., Carbonell, J.M.: A particle finite element method for analysis of industrial forming processes. Computational Mechanics 54(1), 85-107 (2014)

27. Oñate, E., Idelsohn, S.: The particle finite element method. an overview. International Journal of Computational Methods 1, 267-307 (2004)

28. Pozo, D., Salazar, F., Toledo, M.: Modeling the hydraulic performance of the aeration system in dam bottom outlets using the particle finite element method. Revista Internacional de Métodos Numéricos para Cálculo y Diseño en Ingeniería 30(1), 51-59 (2014). [in Spanish]

29. Ribó, R., Pasenau, M., Escolano, E., Ronda, J., González, L.: GiD reference manual. CIMNE, Barcelona (1998)

30. Riquelme, F., Morán, R., Salazar, F., Celigueta, M., Oñate, E.: Flat-seat round-section valves: design criteria and performance analysis via numerical modelling. In: Dam Maintenance and Rehabilitation II, pp. 609-615. CRC Press (2011). [in Spanish]

31. Safavi, K., Zarrati, A., Attari, J.: Experimental study of air demand in high head gated tunnels. In: Proceedings of the Institution of Civil Engineers-Water Management, vol. 161, pp. 105-111. Thomas Telford Ltd (2008)

32. Sagar, B.: Asce hydrogates task committee design guidelines for high-head gates. Journal of Hydraulic Engineering 121(12), 845-852 (1995)

33. Salazar, F., Irazábal, J., Larese, A., Oñate, E.: Numerical modelling of landslide-generated waves with the particle finite element method (PFEM) and a non-Newtonian flow model. International Journal for Numerical and Analytical Methods in Geomechanics (2015)

34. Salazar, F., Oñate, E., Morán, R.: Numerical modelling of landslides in reservoirs via the particle finite element method (PFEM). Revista Internacional de Métodos Numéricos para Cálculo y Diseño en Ingeniería 28(2), 112-123 (2012). [in Spanish]

35. Sharma, H.R.: Air-entrainment in high head gated conduits. Journal of the Hydraulics Division 102(11), 1629-1646 (1976)

36. Spanish National Comittee on Large Dams (SPANCOLD): Dam Safety Technical Guide n. 5 "Spillways and Bottom Outlets". Colegio de Ingenieros de Caminos, Canales y Puertos (1997). [in Spanish]

37. Toombes, L., Chanson, H.: Free-surface aeration and momentum exchange at a bottom outlet. Journal of Hydraulic Research 45(1), 100-110 (2007)

38. Tullis, B.P., Larchar, J.: Determining air demand for small-to medium-sized embankment dam low-level outlet works. Journal of Irrigation and Drainage Engineering 137(12), 793-800 (2011)

39. USACE: Hydraulic Design Criteria, Air Demand, Regulated Outlet Works. US Army Corps of Engineer (1964) 
40. Valero, D., García-Bartual, R.: Calibration of an air entrainment model for cfd spillway applications. In: Advances in Hydroinformatics, pp. 571-582. Springer (2016)

41. Vischer, D., Hager, W.H., Cischer, D.: Dam hydraulics. Wiley Chichester, UK (1998)

42. Wright, N., Tullis, B.: Prototype and laboratory low-level outlet air demand comparison for small-to-medium-sized embankment dams. Journal of Irrigation and Drainage Engineering 140(6), 04014,013 (2014)

43. Zienkiewicz, O.C., Taylor, R.L.: The finite element method for solid and structural mechanics. Butterworth-Heinemann (2005) 